\title{
The digestive tract as the origin of systemic inflammation
}

Petrus R. de Jong ${ }^{1,2^{*}}$, José M. González-Navajas ${ }^{3,4}$ and Nicolaas J. G. Jansen ${ }^{1}$

\begin{abstract}
Failure of gut homeostasis is an important factor in the pathogenesis and progression of systemic inflammation, which can culminate in multiple organ failure and fatality. Pathogenic events in critically ill patients include mesenteric hypoperfusion, dysregulation of gut motility, and failure of the gut barrier with resultant translocation of luminal substrates. This is followed by the exacerbation of local and systemic immune responses. All these events can contribute to pathogenic crosstalk between the gut, circulating cells, and other organs like the liver, pancreas, and lungs. Here we review recent insights into the identity of the cellular and biochemical players from the gut that have key roles in the pathogenic turn of events in these organ systems that derange the systemic inflammatory homeostasis. In particular, we discuss the dangers from within the gastrointestinal tract, including metabolic products from the liver (bile acids), digestive enzymes produced by the pancreas, and inflammatory components of the mesenteric lymph.

Keywords: Acute inflammation, Gastrointestinal failure, Gut-liver crosstalk, Pancreatitis

Abbreviations: ARDS, Acute respiratory distress syndrome; CCK, Cholecystokinin; DCA, Deoxycholic acid; FFA, Free fatty acid; G-I, Gastro-intestinal; GPR, G-protein-coupled receptor; I-BABP, Ileal bile acid-binding protein; ICU, Intensive care unit; IEC, Intestinal epithelial cell; I-FABP, Intestinal fatty acid-binding protein; IL, Interleukin; I/R, Ischemia/reperfusion; KC, Kupffer cell; L-FABP, Liver fatty acid-binding protein; LPS, Lipopolysaccharide; MLN, Mesenteric lymph node; MODS, Multiple organ dysfunction syndrome; PLA2, Phospholipase A2; PRR, Pattern recognition receptor; SCFA, Short-chain fatty acid; STAT3, Signal transducer and activator of transcription 3; TLR, Toll-like receptor; TNF, tumor necrosis factor; UDCA, Ursodeoxycholic acid
\end{abstract}

\section{Background}

Gastro-intestinal (G-I) pathology in the critically ill patient mainly involves the small intestine. The inner lining of the small intestine is covered by a single layer of intestinal epithelial cells (IECs) and is organized as crypts and villi. The crypts are mostly made up of proliferating cells, whereas the villi are covered by fully matured epithelial cells to provide $200-300 \mathrm{~m}^{2}$ of absorptive surface [1]. All IEC types derive from intestinal stem cells that reside at the crypt bottom [2]. Precursor cells differentiate into absorptive enterocytes or one of the secretory cell types. Enterocytes are equipped with

\footnotetext{
* Correspondence: pdejong@sbpdiscovery.org

'Department of Pediatric Intensive Care, Wilhelmina Children's Hospital, University Medical Center Utrecht, Utrecht, The Netherlands

${ }^{2}$ Sanford Burnham Prebys Medical Discovery Institute, 10901 N Torrey Pines

Rd, La Jolla, CA 92037, USA

Full list of author information is available at the end of the article
}

microvilli and express nutrient transporters to maximize the uptake of solutes, simple carbohydrates, and amino acids. Secretory cells include mucus-producing Goblet cells, antimicrobial peptide-producing Paneth cells, and hormone-producing enteroendocrine cells [3]. Products released by secretory cell types are vital for the maintenance of the gut barrier and motility. Paneth cells provide a protective niche for intestinal stem cells and maintain homeostatic host-microbial interactions [4]. These cellular systems provide fail-safe mechanisms to ensure continuous turnover of epithelial cells and maintenance of the intestinal barrier.

The commensal microflora in a healthy gut constitute approximately $10^{3}-10^{4}$ different bacterial species, mostly of the Firmicutes and Bacteroidetes phyla. They are indispensable for the digestion of dietary substrates, exert pro-proliferative effects on IECs, promote enterocyte differentiation, prevent colonization of pathogens, and 
educate the mucosal and systemic immune system [5]. Furthermore, our microbiota is involved in the generation of secondary bile acids, which promote the uptake of dietary lipids and fat-soluble vitamins [6]. The fermentation of complex carbohydrates yields short-chain fatty acids (SCFAs; e.g., butyrate) that serve as an energy source for the host and display beneficial effects on immune cells [5], IEC proliferation, differentiation, and gut barrier function [7]. Importantly, SCFAs also mediate anti-inflammatory effects on immune cells, which involves signaling via G-protein-coupled receptor 41 (GPR41) and GPR43. GPR43 signaling is anti-inflammatory in the gut [8]. However, GPR43 deficiency results in increased mortality upon gut barrier loss, most likely due to septic complications of bacterial translocation associated with aberrant neutrophil chemotaxis [9]. Thus, the intestinal microbiota and its metabolic products are vital for gut homeostasis.

Systemic stress, such as major trauma, burns, or surgery, can disturb this delicate balance, leading to epithelial denudation of villi, enterocyte dysfunction, gut barrier loss, and translocation of luminal constituents to the circulation [10]. This may occur with only mild systemic inflammation, for example, leakage of endotoxins (lipopolysaccharide (LPS)) from the intestinal lumen to the circulation occurs during open heart surgery [11]. On the other hand, a major shift of intestinal microbiota to pathogenic species coinciding with reduced microbial diversity occurs in both systemic inflammatory response syndrome and neonatal sepsis patients [12]. Both Gram-negative bacteria (e.g., Escherichia coli, Klebsiella, Enterobacter spp.) and Gram-positive bacteria (e.g., Staphylococcus, Enterococcus, Streptococcus spp.) play a role in bacteremia or sepsis in neonates [13], infants [14], and adults [15]. Thus, a compromised gut barrier can lead to bacterial translocation and bacteremia, which could lead to systemic inflammation and, in susceptible patients, to sepsis, septic shock, and circulatory collapse, with or without multiple organ dysfunction syndrome (MODS). The role of local events in the intestines, the importance of the gut-liver axis, the contribution of biliary and pancreatic enzymes, and, finally, the gut-lung connection are discussed in the sections below.

\section{Gastrointestinal failure}

The aforementioned deleterious events do not always remain indolent and may lead to the poorly defined clinical entity of G-I failure. Its symptoms include food intolerance, G-I hemorrhage, and ileus. In more severe cases, G-I failure may lead to liver failure, cholecystitis, and pancreatitis $[16,17]$. Postoperative patients frequently experience intestinal failure of various degrees of severity [18]. A grading system of acute G-I injury was recently proposed with increasing severity from grade I (risk of developing G-I dysfunction or failure), grade II (G-I dysfunction), grade III (G-I failure), to grade IV (G-I failure with severe impact on distant organ function) [19]. Early diagnosis of G-I failure is challenging as problems with enteral feeding, including vomiting, delayed gastric emptying, and diarrhea, can occur in up to $50 \%$ of critically ill patients [20]. Since enteral nutrition has beneficial effects on the gut barrier, parenteral feeding may lead to further deterioration of G-I physiology. Gut dysfunction and G-I failure are associated with prolonged intensive care unit (ICU) stay and increased mortality [21, 22]. In fact, the presence of three or more G-I symptoms (high gastric residual volume, absent bowel sounds, vomiting, diarrhea, bowel distension, and G-I bleeding) on the first day of ICU admission is associated with a threefold increase in mortality [23]. To aid in the diagnosis of G-I failure, plasma or urinary levels of intestinal fatty acid-binding protein (I-FABP), liver fatty acid-binding protein (L-FABP) and ileal bile acid-binding protein (I-BABP), and/or citrulline can be helpful $[24,25]$. I-FABP, L-FABP, and I-BABP are reliable biomarkers of enterocyte damage and/or loss and their urinary or plasma levels increase during intestinal injury. Plasma levels of citrulline represent enterocyte mass and/or functionality [26]. In the course of G-I failure, plasma citrulline levels would therefore be decreased and are indicative of a loss of the gut barrier [24, 27]. Indeed, low citrulline levels are associated with elevated serum C-reactive protein (CRP) levels, an increased rate of nosocomial infections, and higher mortality in critically ill patients [28]. A recent report showed that I-FABP can serve as a biomarker for the intensity of intestinal handling during surgery [29]. These serum markers also demonstrated that gut barrier loss is prevalent in patients that underwent non-abdominal surgery [30]. Finally, the systemic release of I-FABP in the course of surgery coincided with endotoxemia [31], whereas the administration of endotoxin in healthy subjects induced an increased intestinal permeability [32]. Together, these data further support the association between gut barrier dysfunction and systemic inflammation, as shown in Fig. 1.

\section{Early event: loss of the gut barrier}

The gut barrier must be permissible to allow uptake of essential nutrients, but also needs to retain harmful substances that are only micrometers away from the circulation. These include microbial substrates (e.g., LPS), dietary components (e.g., free fatty acids (FFAs)) and digestive enzymes produced by the exocrine pancreas. The main etiological factors that contribute to gut barrier loss after surgery are splanchnic hypoperfusion (including ischemia/reperfusion damage) [30], decreased gut motility, and hypoxia. These processes are under control of neuronal and endocrine effector arms, in addition to local control mechanisms, which also affect the 


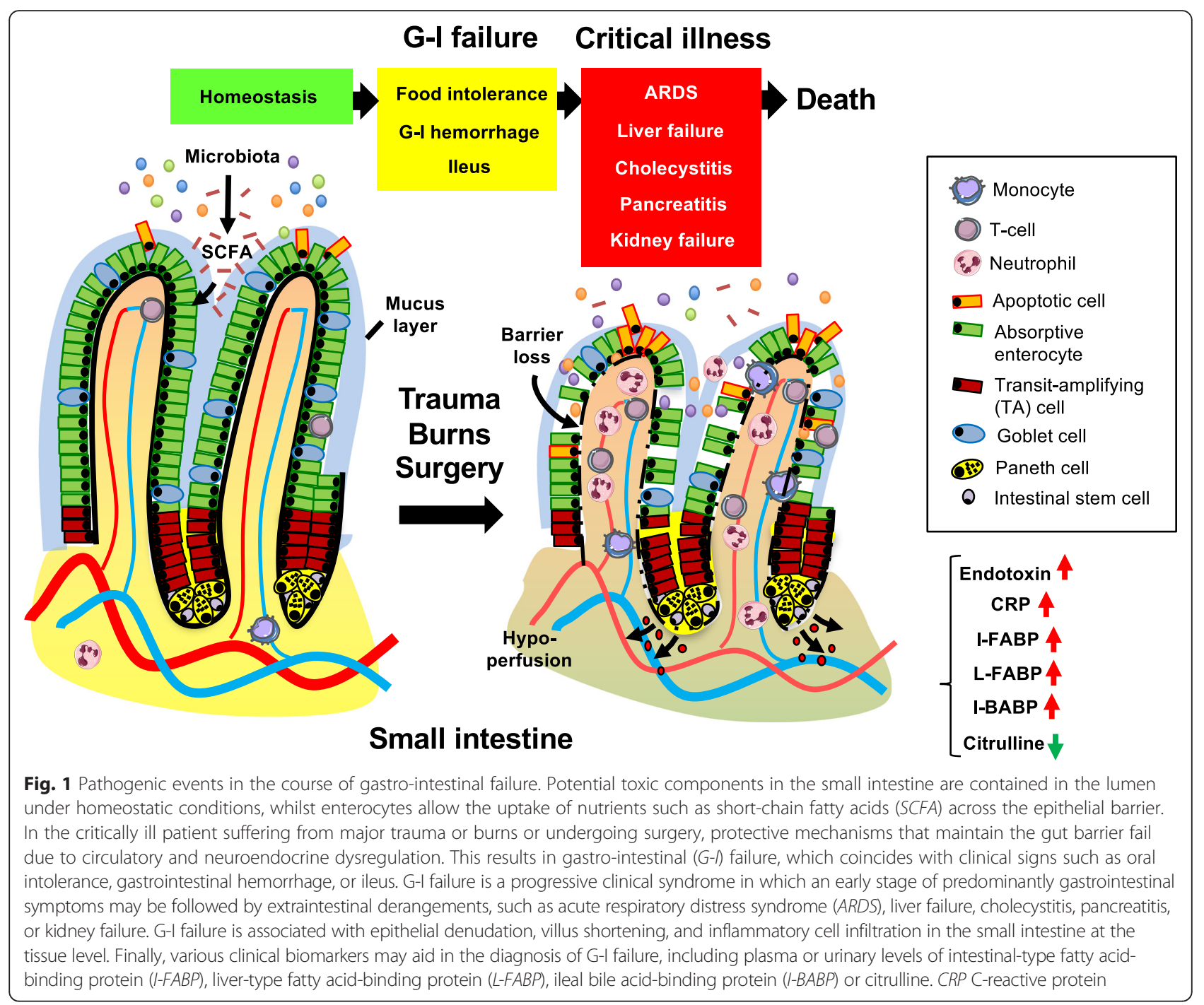

microcirculation. Hypotension associated with systemic inflammatory response syndrome usually results in shunting of blood from the splanchnic vessels to the central circulation. The perfusion of the small intestine operates within tight margins; the lack of autoregulatory mechanisms results in a hypersensitivity to variations in blood pressure. The combination of hypoperfusion and hypoxia can further exacerbate the deleterious effects on intestinal tissue integrity [33]. Hypoperfusion and ischemia/reperfusion $(I / R)$ injury are partners in crime with regard to intestinal pathology [34], even though the latter displays distinct features. Importantly, short periods of $I / R$ did not induce intestinal inflammatory responses in human [35], suggesting that a certain threshold of injury is required for the instigation of G-I failure. An adequate microcirculation is also required for optimal blood flow to tissues, particularly in the G-I tract. Various clinical tools are available to monitor the microcirculation, including orthogonal polarization spectral and sidestream darkfield imaging [36]. Finally, the severity and/or duration of intestinal ischemia are directly correlated with the degree of gut barrier loss and endothelial dysfunction [37]. The reticulo-endothelial system in the liver provides a failsafe mechanism to filter out any toxic translocation products from the portal circulation that leaked from the intestines. However, Kupffer cells (KCs) of the liver-which are key players in the reticulo-endothelial system-appear to play a dual role in the regulation of inflammation. Whereas KCs are an important source of proinflammatory cytokines in systemic inflammation [38], they may also play an anti-inflammatory role under these conditions $[39,40]$. Finally, a portion of potentially deleterious elements can also find a shortcut to the circulation via the mesenteric lymph.

\section{The gut-liver axis in systemic inflammation}

The portal vein works as a major expressway from the spleen and G-I tract to the liver, accounting for 
approximately $70 \%$ of the hepatic blood supply. This anatomical situation makes the liver a central location for clearing systemic bacterial infections and for maintaining immune system homeostasis. Lining the hepatic sinusoids, KCs are the first macrophage population to encounter bacteria or microbial products derived from the intestine. However, the function of KCs is compromised in patients with advanced liver disease and, despite the threatening consequences of impaired liver function, systemic infections are the main cause of death in these patients [41]. Many of these infections are initiated by translocation of intestinal bacteria and usually result in bacteremia and, in more severe cases, sepsis [42]. Bacterial translocation can be demonstrated by analysis of mesenteric lymphatics or portal vein blood samples. It is important to point out here that, in a classic study, portal vein sampling in trauma patients undergoing laparotomy did not provide evidence for bacterial translocation by blood cultures [43]. Subsequent studies with trauma patients confirmed that blood cultures generally failed to show bacterial growth $[44,45]$. However, more sensitive methods, such as immunostaining for $E$. coli beta-galactosidase [44] or electron microscopy [45], provided direct evidence for bacterial translocation to mesenteric lymph nodes (MLNs) in most patients. While the presence of bacteria in MLNs as a pathological event has been debated $[46,47]$, multiple studies have shown that positive cultures from MLN samples obtained from laparotomy patients occurred in $10-15 \%$ of patients, which correlated with an increased risk of postoperative sepsis $[48,49]$ or postoperative infection [50].

Both human and animal model studies have provided more mechanistic details on gut-liver crosstalk (Table 1).
Bacteremia increases the risk of spontaneous bacterial peritonitis, which occurs in one out of five hospitalized cirrhotic patients [51]. At the same time, microbiotadriven inflammation can also aggravate liver disease. For example, alterations in colonic microbiota are associated with endotoxemia and inflammation in patients with hepatic encephalopathy, a complication of liver cirrhosis $[52,53]$. Gut bacteria dysbiosis may also contribute to postoperative infections and organ rejection after liver transplant [54]. In fact, acute liver rejection in rats is accompanied by alterations in gut microbiota, impaired integrity of the intestinal barrier, bacterial translocation, elevation of plasma endotoxin levels, and a systemic inflammatory response $[55,56]$. Gut microbiota dysbiosis can also trigger local inflammation in the liver and promote the progression from moderate liver disease to steatohepatitis [57]. A recent study showed that microbiota-dependent activation of the chemokine receptor CX3CR1 in intestinal macrophages is crucial for maintaining intestinal homeostasis and barrier integrity and, therefore, for controlling steatohepatitis progression [58]. Since advanced liver disease usually leads to circulatory abnormalities (portal hypertension, splanchnic vasodilation), these events may constitute a vicious circle. Damage to the intestinal barrier leads to bacterial translocation and thus liver inflammation and liver dysfunction, leading to exacerbation of circulatory abnormalities and causing further intestinal injury [59].

Emphasizing the relationship between microbiota and the immune response in the liver, recent data suggest that the liver remains sterile when the intestine is healthy. However, the liver becomes an important "secondary firewall" when commensal bacteria penetrate the mesenteric

Table 1 Gut-liver crosstalk in systemic inflammation

\begin{tabular}{|c|c|c|}
\hline Major finding & Study type & Reference \\
\hline Bacteremia due to bacterial translocation is associated with an increased risk of bacterial peritonitis & Human & {$[51]$} \\
\hline Hepatic encephalopathy is associated with changes in the intestinal microbiota & Human & {$[52]$} \\
\hline $\begin{array}{l}\text { Acute liver rejection is associated with changes in intestinal microbiota, loss of gut barrier, and enhanced } \\
\text { systemic inflammation }\end{array}$ & Rodent & {$[55,56]$} \\
\hline CX3CR1 signaling by intestinal macrophages regulates steatohepatitis & Rodent & {$[58]$} \\
\hline A hepatic vascular and phagocytic network functions as a "secondary firewall" to filter escaped gut commensals & Rodent & {$[60]$} \\
\hline Liver cirrhosis is associated with increased inflammasome activation in ascitic fluid macrophages & Human & {$[61]$} \\
\hline Translocation of bacterial DNA in liver cirrhosis is associated with enhanced systemic inflammatory activity & Human & {$[62,63]$} \\
\hline Hepatic STAT3 signaling protects against systemic inflammation caused by polymicrobial sepsis & Rodent & {$[72]$} \\
\hline Hepatic gp130-STAT3 signaling induces myeloid-derived suppressor cells that protect against polymicrobial sepsis & Rodent & {$[73]$} \\
\hline Hepatic STAT3 signaling regulates cellular and humoral pulmonary immunity against bacterial infection & Rodent & {$[74]$} \\
\hline $\begin{array}{l}\text { The liver enhances and protects against systemic inflammation through Kupffer cell-mediated cytokine production } \\
\text { and detoxification by parenchymal cells, respectively }\end{array}$ & Rodent & {$[76]$} \\
\hline Kupffer cells aggravate lung damage in acute pancreatitis & Rodent & {$[78,79]$} \\
\hline
\end{tabular}

Summary of key studies that addressed the bidirectional gut-liver crosstalk in the pathogenesis of systemic inflammation. The type of study (animal model or human) is indicated

STAT3 signal transducer and activator of transcription 3 
circulation [60]. Importantly, not only viable bacteria but also abnormal amounts of microbial products (e.g., LPS or bacterial DNA) can breach the intestine and arrive at the liver or the ascitic fluid. These events have been associated with activation of the inflammasome complex [61], systemic inflammatory responses [62, 63], and acute-on-chronic liver failure [64]. The microbial antigens are recognized by pattern recognition receptors (PRRs), namely Toll-like receptors (TLRs), which in the liver are expressed on KCs, hepatic stellate cells, intrahepatic lymphocytes, dendritic cells, endothelial cells, and hepatocytes [65]. TLR-mediated activation of hepatic stellate cells is associated with the production of proinflammatory cytokines [66] and the development of liver fibrosis [67]. KCs normally produce proinflammatory cytokines and promote immune cell recruitment after TLR stimulation; however, continuous stimulation of KCs with low levels of LPS induces LPS tolerance and release of anti-inflammatory cytokines such as interleukin (IL)-10 [68]. Furthermore, in the healthy liver LPS is detoxified by both KCs and hepatocytes and rapidly loses its biological activity. Thus, it has been speculated that activation of TLR4 on KCs might be a common event and play a role in immune homeostasis, whereas activation of other PRRs, like NOD-like receptors, may be more frequent in infection [54]. Several studies also pointed to crosstalk between KCs and migrating neutrophils. Bactericidal neutrophils migrate to the liver sinusoids during endotoxemia and sepsis and, along with $\mathrm{KCs}$, form the leading force in the elimination of bacteria in the liver [69]. In turn, elimination of neutrophils is necessary to resolve inflammation and previous studies suggested that KCs ingest and eliminate neutrophils in the liver sinusoids after microbial clearance [70]. These interactions may play a critical role in downregulating pro-inflammatory cytokine and chemokine production by KCs [71].

The liver also maintains immune homeostasis in other organs, with an important role for hepatocyte signal transducer and activator of transcription 3 (STAT3) during sepsis and pneumonia. Hepatic STAT3 activity was necessary to prevent an excessive systemic inflammatory response and attenuate lethality after cecal ligation and puncture-induced sepsis [72]. STAT3-mediated protection in this model of polymicrobial sepsis was attributed to the serum amyloid A and CXCL1-dependent mobilization of myeloid-derived suppressor cells [73]. Similarly, a recent study showed that pre-existing liver STAT3 activation modulates host immune responses in a two-hit model of endotoxemia followed by bacterial lung challenge [74]. Mice with hepatocyte-specific STAT3 deletion showed reduced concentrations of acute phase response proteins serum amyloid A and serum amyloid P, impaired alveolar macrophage reactive oxygen species generation, higher lung and blood bacterial loads, and increased mortality in this model [74]. Thus, physiological amounts of bacterial ligands arriving at the liver from the gut can contribute to maintain systemic immune homeostasis through the induction of STAT3 activity. However, gut alterations and excessive microbiota-dependent liver inflammation may shift this balance towards a more proinflammatory phenotype, leading to damage in remote organs such as brain, lung, pancreas, and heart [75]. A good example of this crosstalk is the gut-liver-lung axis during acute pancreatitis, leading to the acute respiratory distress syndrome (ARDS) and MODS. In this scenario, severe pancreatitis triggers intestinal barrier dysfunction and gut inflammation. Translocated microbial products and inflammatory mediators produced in the gut (e.g., tumor necrosis factor (TNF)- $\alpha$, IL-6, and IL-1 $\beta$ ) then arrive at the liver via the portal vein and activate $\mathrm{KCs}$, which produce more pro-inflammatory cytokines that amplify the inflammatory response [76]. These cytokines released by the liver are then transported via the systemic circulation to the lung, where they cause acute hemorrhagic necrosis of lung epithelial cells and activation of pulmonary monocytes and macrophages, ultimately contributing to ARDS and MODS [77, 78]. Indeed, inhibition of KCs has been shown to reduce pancreatitisassociated remote organ injury [78, 79]. Together, these studies suggest that failure of the gut barrier may constitute a fatal event in patients with end-stage liver disease and that the "gut-liver inflammation" axis may play an important role in the balance between tolerance and systemic inflammation in critical illness.

\section{Intestinal damage induced by bile acids}

In addition to the liver serving as a secondary firewall, there is strict compartmentalization of secretions of the biliary tract and exocrine pancreas. Bile acids and pancreatic enzymes are excreted through the pancreatic duct to promote the digestion and uptake of lipids, carbohydrates, and amino acids. Primary bile acids are synthesized in the liver as derivatives of cholesterol, e.g., cholic acid and chenodeoxycholic acid. These are converted by the intestinal microflora to yield secondary bile acids, deoxycholic acid (DCA), lithocholic acid, and ursodeoxycholic acid (UDCA) [80]. Bile is released in the duodenal lumen in response to cholecystokinin (CCK) produced by duodenal cells postprandially [81]. The bile acids are reabsorbed with dietary lipids and returned to the liver via the enterohepatic circulation, whereas saturated digestive enzymes are normally excreted and eliminated [80]. However, under certain conditions bile acids may pave the way for proteases to breach the gut barrier and cause systemic inflammatory responses. Importantly, the different types of bile acids have differential effects on the gut barrier. For example, whereas cholic acid, DCA, and chenodeoxycholic acid showed disruptive effects 
on the intestinal epithelial barrier in vitro, this was not the case for UDCA [82]. Furthermore, exposure of epithelial cells to concentrations of DCA corresponding to high-fat diets disrupted the epithelial barrier in vitro and in vivo. In contrast, concentrations of DCA typically found in low-fat diets did not affect the epithelial integrity [83]. In this context, the effects of enteral nutrition versus total parenteral nutrition on the gut barrier in critically ill patients are highly relevant. Total parenteral nutrition increases the gut permeability, which in addition to the effects of bile acids may involve a variety of mechanisms [84]. Others showed protective effects of lipid-rich enteral feeding on the gut barrier in experimental shock, which was reversed by CCK receptor antagonists [85]. These data suggest an intrinsic protective effect of enteral nutrition on the gut barrier. Thus, even though enteral feeding stimulates the release of bile acids in the gut lumen that could potentially damage the epithelial lining, its advantageous effects on the gut barrier appear to be dominant.

\section{Intestinal and extra-intestinal injury caused by pancreatic enzymes}

The local and systemic effects of pancreatic enzymes in the critically ill patient have recently regained attention. Acinar cells of the exocrine pancreas secrete a variety of enzymes that, upon activation in the duodenal lumen, can degrade proteins (trypsinogen, chymotrypsinogen, carboxypeptidase, elastases), lipids (pancreatic lipase, phospholipase), and sugars (pancreatic amylase). Bicarbonate $\left(\mathrm{HCO}_{3}^{-}\right)$is produced by ductal cells. This pancreatic juice is secreted in response to CCK. However, during intestinal ischemia these proteases can contribute to degradation of the protective mucus layer and epithelial tight-junctions, leading to an elevated gut permeability and penetration of serine proteases of the gut wall [86]. This was first demonstrated by pancreatic duct ligation, which reduced gut barrier failure in an experimental model of hemorrhage-associated shock [87]. Prevention of pancreatic enzyme influx in the intestinal lumen resulted in reduced degradation of the mucus layer, less toxicity to endothelial cells, and reduced activation of circulating neutrophils [87]. The toxic effects of pancreatic enzymes in vivo, including trypsin, chymotrypsin, elastase, amylase, and lipase, are potentiated when the mucus layer is already compromised [88]. Conversely, the addition of a mucus layer to IEC monolayers reduced the disruptive effects of trypsin on the gut barrier [89]. Importantly, the translocation of active proteases to the circulation is associated with an increased risk of multiorgan failure [90], most likely caused by local autodigestive processes in the gut that liberate tissue or microbial factors that turn on systemic inflammatory responses [91]. These data suggest that pharmacological inhibition of pancreatic enzymes could abrogate these pathophysiological events and ameliorate circulatory derangement in critical illness. A recent publication demonstrated this concept in three models of experimental shock in rats-hemorrhagic shock, peritonitis, and endotoxin shock-with a focus on serine proteases. All models of shock resulted in increased protease activity in the gut wall. Conversely, intraluminal administration of protease inhibitors (ANGD, tranexamic acid, and aprotinin) dramatically reduced tissue damage in the small intestines as well as distant organs (heart, lung), which was associated with significantly improved survival [92]. Notably, direct and invasive administration of protease inhibitors was required to yield high intraluminal concentrations in the gut [92], which limits its direct translation into clinical practice. Alternatively, continuous delivery of protease inhibitors via enteral feeding has been shown to be successful in one case of septic shock [93]. Together, these data suggest that under ischemic conditions in the gut, pancreatic enzymes can mediate deleterious local and systemic effects in the critically ill patient, as summarized in Fig. 2.

\section{The gut-lung connection: mesenteric lymph}

A direct anatomical link between the gut, systemic circulation, and distant organs is provided by the lymphatic vessels from the intestines. After feeding, the mesenteric lymph is enriched for lipids (chylomicrons), fat-soluble vitamins, and a variety of other lipophilic macromolecules. These afferent lymphatic vessels drain from the intestinal villus tips to MLNs and ultimately into the thoracic duct, heart, and the pulmonary circulation. Within this network, MLNs are the site where luminal antigens are filtered and taken up by antigen-presenting cells (macrophages, dendritic cells), which can direct adaptive immune responses. The cellular players of this specialized mucosal immune system shuttle between MLNs and the lamina propria and are programmed for successful compartmentalization of the commensal microflora. One of the mechanisms involved in this process is the deposition of secretory IgA in the mucus layer [94], an adaption to the unusually large bacterial load of the G-I tract.

Mesenteric lymph avoids the portal circulation and thus bypasses the reticulo-endothelial system in the liver, i.e., the secondary firewall mediated by KCs. Any unfiltered luminal constituents, such as endotoxins and pancreatic enzymes, in addition to locally produced cytokines and activated immune cells that exit the MLN, are able to directly leak to the circulation. Cytotoxic factors from mesenteric lymph will make their first pass through the pulmonary circulation. Direct toxic effects on the pulmonary endothelium can then cause acute lung injury, culminating in ARDS [95]. This is known as the gut-lymph-lung axis. Indeed, abrogation of mesenteric lymph drainage 


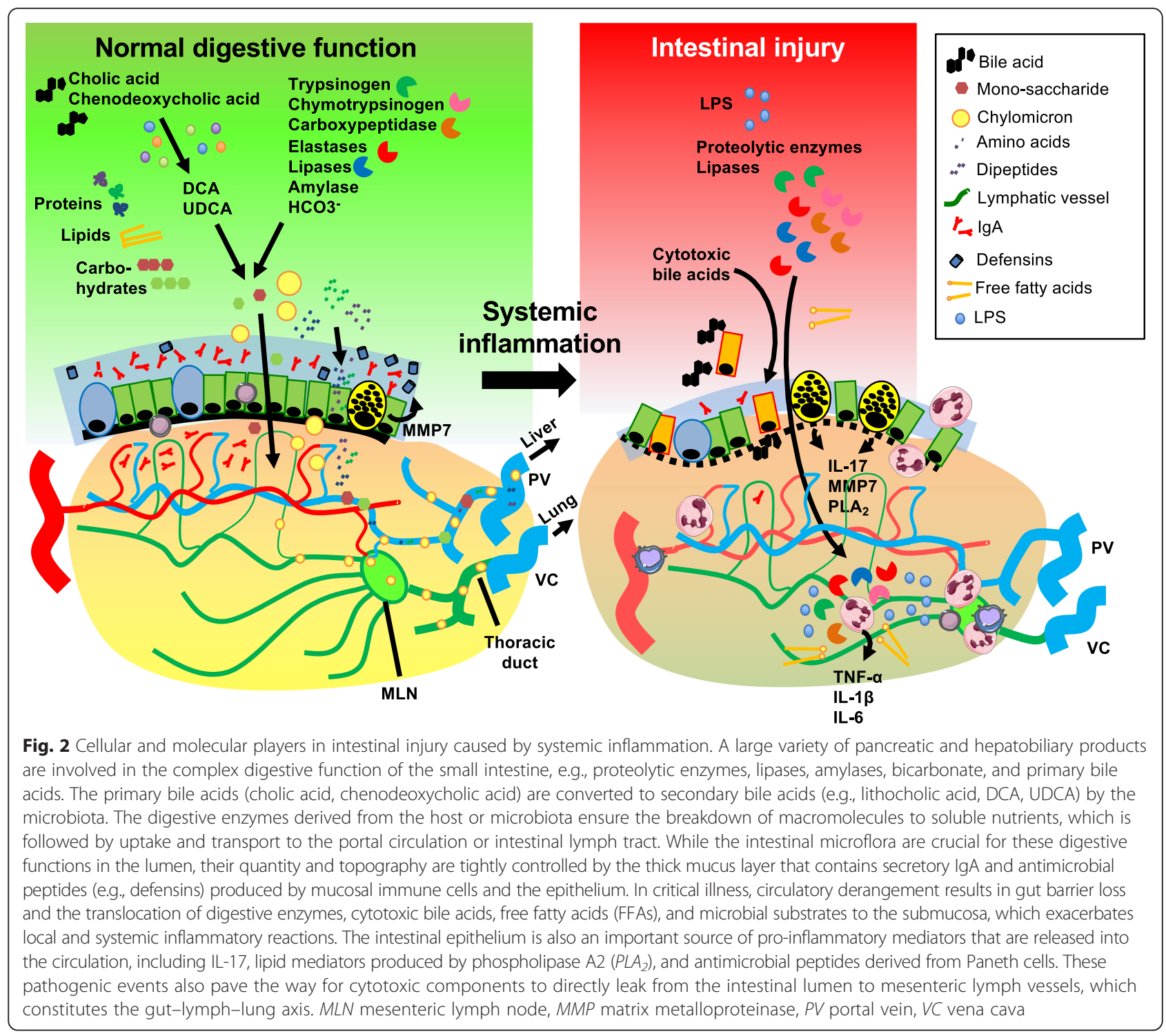

prevented hemorrhagic shock-induced endothelial hyperpermeability and lung damage [96]. Furthermore, realtime cross-transfusion of mesenteric lymph from donor rats with trauma/hemorrhagic shock to naïve recipients resulted in marked lung injury and local neutrophil accumulation in these recipients [97]. Virtually all studies that have addressed the components of mesenteric lymph used animal models (Table 2); there is little information regarding the toxic components of post-shock mesenteric lymph in human [98]. Bacteria or microbial products do not play a role in this phenomenon [99]. Rather, various acute-phase proteins, possibly produced by the intestinal epithelium [100], in addition to pro-inflammatory lipid mediators [101], and in particular lipase-generated FFAs [102], are likely causative agents. Their cytotoxicity appears to be determined by the FFA-to-protein ratio in mesenteric lymph, as the addition of albumin-a lipid scavenger-reversed their effects [102]. Serum albumin precursor was the most (approximately eightfold) upregulated protein in post-shock mesenteric lymph [100], which could therefore be part of a compensatory mechanism to inhibit lipid cytotoxicity [103]. On the other hand, glycosylated albumin in post-shock mesenteric lymph has been associated with intrinsic cytotoxicity [104]. Thus, albumin can have both protective and deleterious effects on lung injury.

Another candidate to mediate the toxic effects of mesenteric lymph is phospholipase A2 $\left(\mathrm{PLA}_{2}\right)$, an enzyme that generates lipid mediators (eicosanoids, prostaglandins) [105]. Importantly, high levels of PLA $_{2}$ are synthesized and secreted by Paneth cells in the intestine [106]. Another antimicrobial protein produced by Paneth cells that was found to be increased in toxic mesenteric lymph was $\alpha$-defensin 4 [107]. Together, this suggests a 
Table 2 Gut-lung crosstalk

\begin{tabular}{|c|c|c|}
\hline Major finding & Study type & Reference \\
\hline Cross-transfusion of mesenteric lymph from donors after shock/trauma induces acute lung injury in recipients & Rodent & [97] \\
\hline Post-shock mesenteric lymph contains increased amounts of bioactive lysophospholipids and PUFAs & Rodent & [101] \\
\hline Post-shock mesenteric lymph contains increased amounts of free fatty acids & Rodent & [102] \\
\hline The detrimental effects of post-shock mesenteric lymph can be reversed by the addition of albumin & Rodent & [103] \\
\hline Inhibition of PLA 2 inhibits the cytotoxic activity of post-shock mesenteric lymph & Rodent & [105] \\
\hline Levels of Paneth cell-derived a-defensin 4 (an antimicrobial peptide) are increased in post-shock mesenteric lymph & Rodent & [107] \\
\hline Endogenous alarmins are abundantly released from the intestines in post-shock mesenteric lymph & Rodent & [113] \\
\hline
\end{tabular}

Pertinent studies that addressed the interactions between intestinal pathology and lung injury

$P L A_{2}$ phospholipase A2, PUFA poly-unsaturated fatty acids

potential detrimental role for Paneth cell products in the course of systemic inflammation and/or shock, which are distributed via the intestinal lymphatic system to the circulation. Indeed, mice deficient for matrix metalloproteinase 7 (MMP7), the enzyme involved in posttranslational activation of Paneth cells products, were protected against systemic LPS-induced lethality [108]. Activation of Paneth cells and transport of Paneth cell products, including pro-inflammatory IL-17A, by intestinal macrophages to the liver have been previously demonstrated in systemic inflammation [109]. IL-17 is an important activator of neutrophils and Paneth cells were the main producers of IL-17 in an experimental model of TNF- $\alpha$-induced intestinal injury and shock [110]. Furthermore, liver I/R injury and its associated systemic inflammation resulted in significantly increased IL-17 levels in the portal venous blood, which was associated with massive Paneth cell degranulation in the gut and hepatic, intestinal, and

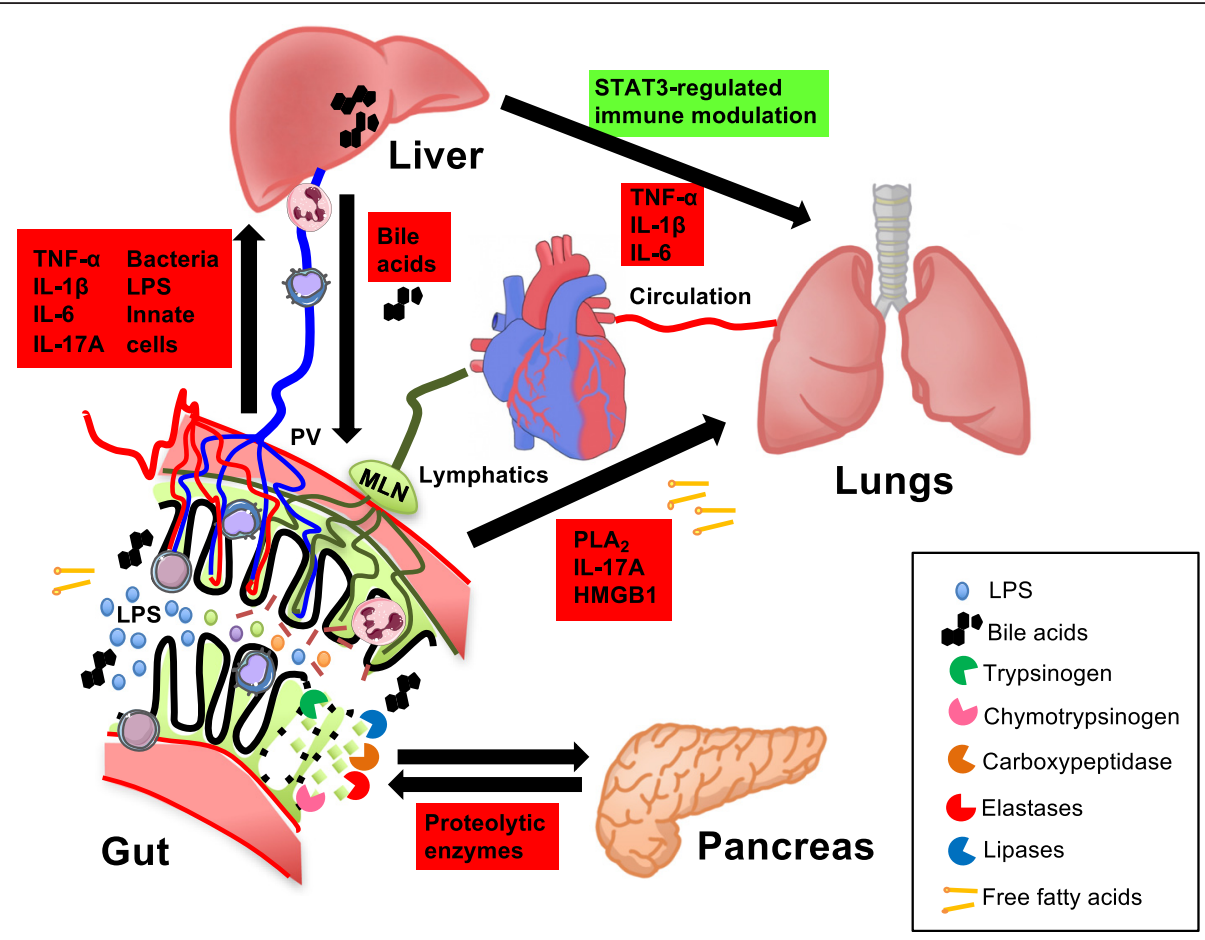

Fig. 3 Direct and indirect interactions between the gut and other organs in systemic inflammation. Luminal components of the small intestine can spread to the circulation via the portal vein (PV) and liver. This includes pro-inflammatory constituents such as lipopolysaccharide (LPS), bacterial DNA, whole bacteria, other bacterial products, and free fatty acids (FFAs). Toxic components of the gut lumen, including FFAs, inflammatory products of phospholipase A2 $\left(P L A_{2}\right)$, pro-inflammatory cytokines (e.g., IL-17), and damage-associated molecular substrates such as high mobility group box 1 protein (HMGB1), can reach the pulmonary circulation via mesenteric lymph. Bile acids from the liver, including cholic acid, DCA, and chenodeoxycholic acid, mediate cytotoxic effects on intestinal epithelial cells. STAT3 signaling in Kupffer cells (KCs) of the liver maintains tolerance under homeostatic conditions, whereas KCs produce high levels of pro-inflammatory cytokines in systemic inflammation with toxic effects on the lung parenchyma. Finally, activated serine proteases, elastases, and lipases produced by the pancreas can cause local tissue destruction and activation of immune cells in intestinal tissues, leading to exacerbated systemic inflammatory responses 
renal injury. Pharmacological or genetic approaches to abrogate Paneth cell function reversed these effects [111]. Similarly, genetic knockout for IL-17A also prevented intestinal damage in this I/R model [112]. These findings further demonstrate a central role for the gut as a driving force in systemic inflammation (Fig. 2).

Finally, increased levels of alarmins that are generally released after tissue injury were also found to be elevated in post-shock mesenteric lymph [113]. These substrates are endogenous TLR4 ligands and mediate immunostimulatory effects via the activation of nuclear factor kappa $B$ (NF-kB). Mice with genetic mutations in the receptors or adapter molecules from the TLR4 signaling pathway were protected against post-shock mesenteric lymphmediated lung injury [114]. These findings are consistent with the "danger model" that states that certain endogenous ligands signal the presence of tissue injury to the host via PRRs [115], including TLR.

\section{Conclusions}

In conclusion, the mesenteric lymph is another route for immunostimulatory proteins to reach the systemic circulation after intestinal injury and post-shock mesenteric lymph is particularly toxic to the pulmonary microvasculature. Gut-derived toxic factors that leak from MLNs, including products of pancreatic enzymes, endogenous danger signals, and Paneth cell products, most likely partner up to exert these detrimental effects. All the aforementioned interactions are summarized in Fig. 3. Finally, basic insights into the intimate relationship between the G-I tract and the systemic inflammatory system are expected to lead to more efficacious treatment modalities for critical illness in the future.

\section{Acknowledgments}

We thank Asami Takahashi for her assistance in figure preparation.

\section{Funding}

PRdJ was supported by a Research Fellowship from the Crohn's and Colitis Foundation of America (CCFA; RFA2927). JMG-N is supported by grant Pl13/00315 from the Institute of Health Carlos III, Government of Spain (co-financed with FEDER funds) and grant UGP-14-123 from the FISABIO Research Foundation.

\section{Authors' contributions}

PRdJ, JMG-N, and NJGJ contributed equally to the drafting and final review of the manuscript. All authors read and approved the final manuscript.

\footnotetext{
Authors' information

PRdJ studied the regulation of systemic inflammation in pediatric patients at the University Medical Center Utrecht (UMCU), The Netherlands. He completed a research fellowship at the University of California, San Diego (UCSD) that addressed regulatory mechanisms of intestinal inflammation, supported by the Crohn's and Colitis Foundation of America (CCFA). Concurrently he obtained his PhD degree at Utrecht University. He is currently a postdoctoral fellow at the Sanford Burnham Prebys Medical Discovery Institute, La Jolla, CA, USA.

JMG-N received his doctoral degree in Biology from the University of Alicante, Spain. He completed his postdoctoral training in mucosal immunology at UCSD. He is currently a Miguel Servet researcher of the Spanish Institute of Health Carlos III and principal investigator at the
}

Networked Biomedical Research Center for Hepatic and Digestive Diseases (CIBERehd) in Alicante. His laboratory focuses on the regulation of systemic inflammation, as well as inflammation and inflammation-associated cancer of the gut and liver.

NJGJ is an Associate Professor in Pediatric Intensive Care at the Dept. of Pediatrics, UMC Utrecht, The Netherlands. He currently serves as the Chairman of the Section Infection, Systemic Inflammation and Sepsis of the European Society of Pediatric and Neonatal Intensive Care (ESPNIC), has been the ESPNIC Council Member for the Netherlands, and has served as Chairman of the Dutch Society for Pediatric Intensive Care. His research focuses on regulatory mechanisms in systemic inflammation induced by pediatric cardiac surgery and on brain injury during and after pediatric cardiac surgery. He is principal investigator at the Institute of Child Health at the University Medical Center of Utrecht for Congenital Heart Disease LifeSpan and follow-up program.

\section{Competing interests}

The authors declare that they have no competing interests.

\section{Author details}

'Department of Pediatric Intensive Care, Wilhelmina Children's Hospital, University Medical Center Utrecht, Utrecht, The Netherlands. ${ }^{2}$ Sanford Burnham Prebys Medical Discovery Institute, 10901 N Torrey Pines Rd, La Jolla, CA 92037, USA. ${ }^{3}$ Networked Biomedical Research Center for Hepatic and Digestive Diseases (CIBERehd), Hospital General Universitario de Alicante, Alicante, Spain. ${ }^{4}$ Alicante Institute of Health and Biomedical Research (ISABIAL - FISABIO Foundation), Alicante, Spain.

Published online: 18 October 2016

\section{References}

1. van der Flier $L G$, Clevers H. Stem cells, self-renewal, and differentiation in the intestinal epithelium. Annu Rev Physiol. 2009;71:241-60.

2. Sato T, van Es JH, Snippert HJ, Stange DE, Vries RG, van den Born M, Barker N, Shroyer NF, van de Wetering M, Clevers H. Paneth cells constitute the niche for Lgr5 stem cells in intestinal crypts. Nature. 2011;469(7330):415-8.

3. Clevers H, Batlle E. SnapShot: the intestinal crypt. Cell. 2013;152(5):1198. e2.

4. Vaishnava S, Behrendt CL, Ismail AS, Eckmann L, Hooper LV. Paneth cells directly sense gut commensals and maintain homeostasis at the intestinal host-microbial interface. Proc Natl Acad Sci U S A. 2008;105(52):20858-63.

5. Tremaroli $V$, Backhed F. Functional interactions between the gut microbiota and host metabolism. Nature. 2012;489(7415):242-9.

6. Qin J, Li R, Raes J, Arumugam M, Burgdorf KS, Manichanh C, Nielsen T, Pons N, Levenez F, Yamada T, Mende DR, Li J, Xu J, Li S, Li D, Cao J, Wang B, Liang H, Zheng H, Xie Y, Tap J, Lepage P, Bertalan M, Batto JM, Hansen T, Le Paslier D, Linneberg A, Nielsen HB, Pelletier E, Renault P, Sicheritz-Ponten T, Turner K, Zhu H, Yu C, Li S, Jian M, Zhou Y, Li Y, Zhang X, Li S, Qin N, Yang H, Wang J, Brunak S, Dore J, Guarner F, Kristiansen K, Pedersen O, Parkhill J, Weissenbach J, MetaHIT C, Bork P, Ehrlich SD, Wang J. A human gut microbial gene catalogue established by metagenomic sequencing. Nature. 2010;464(7285):59-65.

7. Lewis K, Lutgendorff F, Phan V, Soderholm JD, Sherman PM, McKay DM. Enhanced translocation of bacteria across metabolically stressed epithelia is reduced by butyrate. Inflamm Bowel Dis. 2010;16(7):1138-48.

8. Maslowski KM, Vieira AT, Ng A, Kranich J, Sierro F, Yu D, Schilter HC, Rolph MS, Mackay F, Artis D, Xavier RJ, Teixeira MM, Mackay CR. Regulation of inflammatory responses by gut microbiota and chemoattractant receptor GPR43. Nature. 2009;461(7268):1282-6.

9. Sina C, Gavrilova O, Forster M, Till A, Derer S, Hildebrand F, Raabe B, Chalaris A, Scheller J, Rehmann A, Franke A, Ott S, Hasler R, Nikolaus S, Folsch UR, Rose-John S, Jiang HP, Li J, Schreiber S, Rosenstiel P. G protein-coupled receptor 43 is essential for neutrophil recruitment during intestinal inflammation. J Immunol. 2009;183(11):7514-22.

10. Clark JA, Coopersmith CM. Intestinal crosstalk: a new paradigm for understanding the gut as the "motor" of critical illness. Shock. 2007;28(4):384-93.

11. Kats S, Schonberger JP, Brands R, Seinen W, van Oeveren W. Endotoxin release in cardiac surgery with cardiopulmonary bypass: pathophysiology and possible therapeutic strategies. An update. Eur I Cardiothorac Surg. 2011;39(4):451-8.

12. Madan JC, Salari RC, Saxena D, Davidson L, O'Toole GA, Moore JH, Sogin ML, Foster JA, Edwards WH, Palumbo P, Hibberd PL. Gut microbial 
colonisation in premature neonates predicts neonatal sepsis. Arch Dis Child Fetal Neonatal Ed. 2012;97(6):F456-62.

13. Hsu JF, Chu SM, Lee CW, Yang PH, Lien R, Chiang MC, Fu RH, Huang HR, Tsai $\mathrm{MH}$. Incidence, clinical characteristics and attributable mortality of persistent bloodstream infection in the neonatal intensive care unit. PLoS One. 2015;10(4):e0124567.

14. Pereira CA, Marra AR, Camargo LF, Pignatari AC, Sukiennik T, Behar PR, Medeiros EA, Ribeiro J, Girao E, Correa L, Guerra C, Carneiro I, Brites C, Reis M, de Souza MA, Tranchesi R, Barata CU, Edmond MB, Brazilian SCOPE Study Group. Nosocomial bloodstream infections in Brazilian pediatric patients: microbiology, epidemiology, and clinical features. PLoS One. 2013;8(7):e68144.

15. Phua J, Ngerng W, See K, Tay C, Kiong T, Lim H, Chew M, Yip H, Tan A, Khalizah H, Capistrano R, Lee K, Mukhopadhyay A. Characteristics and outcomes of culture-negative versus culture-positive severe sepsis. Crit Care. 2013;17(5):R202.

16. Ohri SK, Velissaris T. Gastrointestinal dysfunction following cardiac surgery. Perfusion. 2006;21(4):215-23.

17. Reintam A, Parm P, Kitus R, Starkopf J, Kern H. Gastrointestinal failure score in critically ill patients: a prospective observational study. Crit Care. 2008;12(4):R90

18. Carlson GL, Dark P. Acute intestinal failure. Curr Opin Crit Care. 2010;16(4):347-52

19. Reintam Blaser A, Malbrain ML, Starkopf J, Fruhwald S, Jakob SM, De Waele J, Braun JP, Poeze M, Spies C. Gastrointestinal function in intensive care patients: terminology, definitions and management. Recommendations of the ESICM Working Group on Abdominal Problems. Intensive Care Med. 2012;38(3):384-94

20. Mentec H, Dupont H, Bocchetti M, Cani P, Ponche F, Bleichner G. Upper digestive intolerance during enteral nutrition in critically ill patients: frequency, risk factors, and complications. Crit Care Med. 2001;29(10):1955-61.

21. Reintam A, Parm P, Redlich U, Tooding LM, Starkopf J, Kohler F, Spies C, Kern $\mathrm{H}$. Gastrointestinal failure in intensive care: a retrospective clinical study in three different intensive care units in Germany and Estonia. BMC Gastroenterol. 2006;6:19.

22. Silva MA, Santos Sda G, Tomasi CD, Luz G, Paula MM, Pizzol FD, Ritter C. Enteral nutrition discontinuation and outcomes in general critically ill patients. Clinics (Sao Paulo). 2013;68(2):173-8.

23. Reintam Blaser A, Poeze M, Malbrain ML, Bjorck M, Oudemans-van Straaten HM, Starkopf J, Gastro-Intestinal Failure Trial Group. Gastrointestinal symptoms during the first week of intensive care are associated with poor outcome: a prospective multicentre study. Intensive Care Med. 2013:39(5):899-909.

24. Piton G, Manzon C, Cypriani B, Carbonnel F, Capellier G. Acute intestinal failure in critically ill patients: is plasma citrulline the right marker? Intensive Care Med. 2011;37(6):911-7.

25. Thuijls G, van Wijck K, Grootjans J, Derikx JP, van Bijnen AA, Heineman E, Dejong $\mathrm{CH}$, Buurman WA, Poeze M. Early diagnosis of intestinal ischemia using urinary and plasma fatty acid binding proteins. Ann Surg. 2011;253(2):303-8.

26. Derikx JP, Blijlevens NM, Donnelly JP, Fujii H, Kanda T, van Bijnen AA, Heineman E, Buurman WA. Loss of enterocyte mass is accompanied by diminished turnover of enterocytes after myeloablative therapy in haematopoietic stem-cell transplant recipients. Ann Oncol. 2009;20(2):337-42.

27. Typpo KV, Larmonier CB, Deschenes J, Redford D, Kiela PR, Ghishan FK Clinical characteristics associated with postoperative intestinal epithelial barrier dysfunction in children with congenital heart disease. Pediatr Crit Care Med. 2015;16(1):37-44.

28. Piton G, Manzon C, Monnet E, Cypriani B, Barbot O, Navellou JC, Carbonnel F, Capellier G. Plasma citrulline kinetics and prognostic value in critically ill patients. Intensive Care Med. 2010;36(4):702-6.

29. van Bree SH, Cailotto C, Di Giovangiulio M, Jansen E, van der Vliet J, Costes L, Depoortere I, Gomez-Pinilla PJ, Matteoli G, Boeckxstaens GE. Systemic inflammation with enhanced brain activation contributes to more severe delay in postoperative ileus. Neurogastroenterol Motil. 2013;25(8):e540-9.

30. Derikx JP, van Waardenburg DA, Thuijls G, Willigers HM, Koenraads M, van Bijnen AA, Heineman E, Poeze M, Ambergen T, van Ooij A, van Rhijn LW, Buurman WA. New insight in loss of gut barrier during major nonabdominal surgery. PLoS One. 2008;3(12):e3954.

31. Pathan N, Burmester M, Adamovic T, Berk M, Ng KW, Betts H, Macrae D, Waddell S, Paul-Clark M, Nuamah R, Mein C, Levin M, Montana G, Mitchell JA. Intestinal injury and endotoxemia in children undergoing surgery for congenital heart disease. Am J Respir Crit Care Med. 2011;184(11):1261-9.
32. Hietbrink F, Besselink MG, Renooij W, de Smet MB, Draisma A, van der Hoeven $\mathrm{H}$, Pickkers $\mathrm{P}$. Systemic inflammation increases intestinal permeability during experimental human endotoxemia. Shock. 2009:32(4):374-8.

33. Harrois A, Baudry N, Huet O, Kato H, Lohez M, Ziol M, Duranteau J, Vicaut E. Synergistic deleterious effect of hypoxemia and hypovolemia on microcirculation in intestinal villi*. Crit Care Med. 2013;41(11):e376-84.

34. Feinman R, Deitch EA, Watkins AC, Abungu B, Colorado I, Kannan KB, Sheth SU, Caputo FJ, Lu Q, Ramanathan M, Attan S, Badami CD, Doucet D, Barlos D, Bosch-Marce M, Semenza GL, Xu DZ. HIF-1 mediates pathogenic inflammatory responses to intestinal ischemia-reperfusion injury. Am J Physiol Gastrointest Liver Physiol. 2010;299(4):G833-43.

35. Matthijsen RA, Derikx JP, Kuipers D, van Dam RM, Dejong $\mathrm{CH}$, Buurman WA. Enterocyte shedding and epithelial lining repair following ischemia of the human small intestine attenuate inflammation. PLoS One. 2009;4(9):e7045.

36. Top AP, Tasker RC, Ince C. The microcirculation of the critically ill pediatric patient. Crit Care. 2011;15(2):213.

37. Sun Z, Wang X, Deng X, Lasson A, Wallen R, Hallberg E, Andersson R. The influence of intestinal ischemia and reperfusion on bidirectional intestinal barrier permeability, cellular membrane integrity, proteinase inhibitors, and cell death in rats. Shock. 1998;10(3):203-12.

38. Kim TH, Lee SH, Lee SM. Role of Kupffer cells in pathogenesis of sepsisinduced drug metabolizing dysfunction. FEBS J. 2011;278(13):2307-17.

39. Traeger T, Mikulcak M, Eipel C, Abshagen K, Diedrich S, Heidecke CD, Maier S, Vollmar B. Kupffer cell depletion reduces hepatic inflammation and apoptosis but decreases survival in abdominal sepsis. Eur J Gastroenterol Hepatol. 2010;22(9):1039-49.

40. Hutchins NA, Chung CS, Borgerding JN, Ayala CA, Ayala A. Kupffer cells protect liver sinusoidal endothelial cells from Fas-dependent apoptosis in sepsis by down-regulating gp130. Am J Pathol. 2013;182(3):742-54.

41. Arvaniti V, D'Amico G, Fede G, Manousou P, Tsochatzis E, Pleguezuelo M, Burroughs AK. Infections in patients with cirrhosis increase mortality fourfold and should be used in determining prognosis. Gastroenterology. 2010;139(4):1246-56. 1256.e1-5.

42. Gustot T, Durand F, Lebrec D, Vincent JL, Moreau R. Severe sepsis in cirrhosis. Hepatology. 2009;50(6):2022-33.

43. Moore FA, Moore EE, Poggetti R, McAnena OJ, Peterson VM, Abernathy CM, Parsons PE. Gut bacterial translocation via the portal vein: a clinical perspective with major torso trauma. J Trauma. 1991;31(5):629-36. discussion 636-8

44. Brathwaite CE, Ross SE, Nagele R, Mure AJ, O'Malley KF, Garcia-Perez FA. Bacterial translocation occurs in humans after traumatic injury: evidence using immunofluorescence. J Trauma. 1993;34(4):586-9. discussion 589-90.

45. Reed LL, Martin M, Manglano R, Newson B, Kocka F, Barrett J. Bacterial translocation following abdominal trauma in humans. Circ Shock. 1994:42(1):1-6.

46. Moore FA. The role of the gastrointestinal tract in postinjury multiple organ failure. Am J Surg. 1999;178(6):449-53.

47. MacFie J. Current status of bacterial translocation as a cause of surgical sepsis. Br Med Bull. 2004:71:1-11.

48. O'Boyle CJ, MacFie J, Mitchell CJ, Johnstone D, Sagar PM, Sedman PC. Microbiology of bacterial translocation in humans. Gut. 1998;42(1):29-35.

49. MacFie J, Reddy BS, Gatt M, Jain PK, Sowdi R, Mitchell CJ. Bacterial translocation studied in 927 patients over 13 years. Br J Surg. 2006;93(1):87-93.

50. Nieves E, Tobon LF, Rios DI, Isaza A, Ramirez M, Beltran JA, Garzon-Ospina D, Patarroyo MA, Gomez A. Bacterial translocation in abdominal trauma and postoperative infections. J Trauma. 2011;71(5):1258-61.

51. Bajaj JS, O'Leary JG, Reddy KR, Wong F, Olson JC, Subramanian RM, Brown G, Noble NA, Thacker LR, Kamath PS, NACSELD. Second infections independently increase mortality in hospitalized patients with cirrhosis: the North American consortium for the study of end-stage liver disease (NACSELD) experience. Hepatology. 2012;56(6):2328-35.

52. Bajaj JS, Ridlon JM, Hylemon PB, Thacker LR, Heuman DM, Smith S, Sikaroodi M, Gillevet PM. Linkage of gut microbiome with cognition in hepatic encephalopathy. Am J Physiol Gastrointest Liver Physiol. 2012;302(1):G168-75.

53. Gomez-Hurtado I, Such J, Sanz Y, Frances R. Gut microbiota-related complications in cirrhosis. World J Gastroenterol. 2014;20(42):15624-31.

54. Chassaing B, Etienne-Mesmin L, Gewirtz AT. Microbiota-liver axis in hepatic disease. Hepatology. 2014;59(1):328-39. 
55. Xie Y, Luo Z, Li Z, Deng M, Liu H, Zhu B, Ruan B, Li L. Structural shifts of fecal microbial communities in rats with acute rejection after liver transplantation. Microb Ecol. 2012;64(2):546-54.

56. Ren Z, Jiang J, Lu H, Chen X, He Y, Zhang H, Xie H, Wang W, Zheng S, Zhou L. Intestinal microbial variation may predict early acute rejection after liver transplantation in rats. Transplantation. 2014;98(8):844-52.

57. Henao-Mejia J, Elinav E, Jin C, Hao L, Mehal WZ, Strowig T, Thaiss CA, Kau AL, Eisenbarth SC, Jurczak MJ, Camporez JP, Shulman Gl, Gordon JI, Hoffman HM, Flavell RA. Inflammasome-mediated dysbiosis regulates progression of NAFLD and obesity. Nature. 2012;482(7384):179-85.

58. Schneider KM, Bieghs V, Heymann F, Hu W, Dreymueller D, Liao L, Frissen M, Ludwig A, Gassler N, Pabst O, Latz E, Sellge G, Penders J, Tacke F, Trautwein C. CX3CR1 is a gatekeeper for intestinal barrier integrity in mice: Limiting steatohepatitis by maintaining intestinal homeostasis. Hepatology 2015;62(5):1405-16.

59. Prin M, Bakker J, Wagener G. Hepatosplanchnic circulation in cirrhosis and sepsis. World J Gastroenterol. 2015;21(9):2582-92.

60. Balmer ML, Slack E, de Gottardi A, Lawson MA, Hapfelmeier S, Miele L, Grieco A, Van Vlierberghe H, Fahrner R, Patuto N, Bernsmeier C, Ronchi F, Wyss M, Stroka D, Dickgreber N, Heim MH, McCoy KD, Macpherson AJ. The liver may act as a firewall mediating mutualism between the host and its gut commensal microbiota. Sci Transl Med. 2014;6(237):237ra66.

61. Lozano-Ruiz B, Bachiller V, Garcia-Martinez I, Zapater P, Gomez-Hurtado I, Moratalla A, Gimenez P, Bellot P, Frances R, Such J, Gonzalez-Navajas JM. Absent in melanoma 2 triggers a heightened inflammasome response in ascitic fluid macrophages of patients with cirrhosis. J Hepatol. 2015;62(1):64-71.

62. Frances R, Zapater P, Gonzalez-Navajas JM, Munoz C, Cano R, Moreu R, Pascual S, Bellot P, Perez-Mateo M, Such J. Bacterial DNA in patients with cirrhosis and noninfected ascites mimics the soluble immune response established in patients with spontaneous bacterial peritonitis. Hepatology. 2008;47(3):978-85.

63. Gonzalez-Navajas JM, Bellot P, Frances R, Zapater P, Munoz C, Garcia-Pagan JC, Pascual S, Perez-Mateo M, Bosch J, Such J. Presence of bacterial-DNA in cirrhosis identifies a subgroup of patients with marked inflammatory response not related to endotoxin. J Hepatol. 2008;48(1):61-7.

64. Zapater P, Frances R, Gonzalez-Navajas JM, de la Hoz MA, Moreu R, Pascual S, Monfort D, Montoliu S, Vila C, Escudero A, Torras X, Cirera I, Llanos L, Guarner-Argente C, Palazon JM, Carnicer F, Bellot P, Guarner C, Planas R, Sola R, Serra MA, Munoz C, Perez-Mateo M, Such J. Serum and ascitic fluid bacterial DNA: a new independent prognostic factor in noninfected patients with cirrhosis. Hepatology. 2008;48(6):1924-31.

65. Nakamoto N, Kanai T. Role of toll-like receptors in immune activation and tolerance in the liver. Front Immunol. 2014;5:221.

66. Paik YH, Schwabe RF, Bataller R, Russo MP, Jobin C, Brenner DA. Toll-like receptor 4 mediates inflammatory signaling by bacterial lipopolysaccharide in human hepatic stellate cells. Hepatology. 2003;37(5):1043-55.

67. Seki E, De Minicis S, Osterreicher CH, Kluwe J, Osawa Y, Brenner DA, Schwabe RF. TLR4 enhances TGF-beta signaling and hepatic fibrosis. Nat Med. 2007;13(11):1324-32.

68. Knolle P, Schlaak J, Uhrig A, Kempf P, Meyer zum Buschenfelde KH, Gerken G. Human Kupffer cells secrete IL-10 in response to lipopolysaccharide (LPS) challenge. J Hepatol. 1995;22(2):226-9.

69. Gregory SH, Sagnimeni AJ, Wing EJ. Bacteria in the bloodstream are trapped in the liver and killed by immigrating neutrophils. J Immunol. 1996;157(6): 2514-20.

70. Shi J, Gilbert GE, Kokubo Y, Ohashi T. Role of the liver in regulating numbers of circulating neutrophils. Blood. 2001;98(4):1226-30.

71. Holub M, Cheng CW, Mott S, Wintermeyer P, van Rooijen N, Gregory SH Neutrophils sequestered in the liver suppress the proinflammatory response of Kupffer cells to systemic bacterial infection. J Immunol. 2009;183(5):3309-16.

72. Sakamori R, Takehara T, Ohnishi C, Tatsumi T, Ohkawa K, Takeda K, Akira S, Hayashi N. Signal transducer and activator of transcription 3 signaling within hepatocytes attenuates systemic inflammatory response and lethality in septic mice. Hepatology. 2007;46(5):1564-73.

73. Sander LE, Sackett SD, Dierssen U, Beraza N, Linke RP, Muller M, Blander JM, Tacke F, Trautwein C. Hepatic acute-phase proteins control innate immune responses during infection by promoting myeloid-derived suppressor cell function. J Exp Med. 2010;207(7):1453-64.

74. Hilliard KL, Allen E, Traber KE, Kim Y, Wasserman GA, Jones MR, Mizgerd JP, Quinton LJ. Activation of hepatic STAT3 maintains pulmonary defense during endotoxemia. Infect Immun. 2015;83(10):4015-27.
75. Gonzalez-Reimers E, Santolaria-Fernandez F, Martin-Gonzalez MC, Fernandez-Rodriguez CM, Quintero-Platt G. Alcoholism: a systemic proinflammatory condition. World J Gastroenterol. 2014;20(40):14660-71.

76. Wang Y, Liu W, Liu X, Sheng M, Pei Y, Lei R, Zhang S, Tao R. Role of liver in modulating the release of inflammatory cytokines involved in lung and multiple organ dysfunction in severe acute pancreatitis. Cell Biochem Biophys. 2015;71(2):765-76.

77. Closa D, Bardaji M, Hotter G, Prats N, Gelpi E, Fernandez-Cruz L, RoselloCatafau J. Hepatic involvement in pancreatitis-induced lung damage. Am J Physiol. 1996;270(1 Pt 1):G6-13.

78. Liu HB, Cui NQ, Li DH, Chen C. Role of Kupffer cells in acute hemorrhagic necrotizing pancreatitis-associated lung injury of rats. World J Gastroenterol. 2006:12(3):403-7.

79. Shifrin AL, Chirmule N, Zhang Y, Raper SE. Macrophage ablation attenuates adenoviral vector-induced pancreatitis. Surgery. 2005;137(5):545-51.

80. Martinez-Augustin O, Sanchez de Medina F. Intestinal bile acid physiology and pathophysiology. World J Gastroenterol. 2008;14(37):5630-40.

81. Mossner J. New advances in cell physiology and pathophysiology of the exocrine pancreas. Dig Dis. 2010;28(6):722-8.

82. Raimondi F, Santoro P, Barone MV, Pappacoda S, Barretta ML, Nanayakkara M, Apicella C, Capasso L, Paludetto R. Bile acids modulate tight junction structure and barrier function of Caco-2 monolayers via EGFR activation. Am J Physiol Gastrointest Liver Physiol. 2008:294(4):G906-13.

83. Stenman LK, Holma R, Eggert A, Korpela R. A novel mechanism for gut barrier dysfunction by dietary fat: epithelial disruption by hydrophobic bile acids. Am J Physiol Gastrointest Liver Physiol. 2013;304(3):G227-34.

84. Feng Y, Ralls MW, Xiao W, Miyasaka E, Herman RS, Teitelbaum DH. Loss of enteral nutrition in a mouse model results in intestinal epithelial barrier dysfunction. Ann N Y Acad Sci. 2012;1258:71-7.

85. de Haan JJ, Thuijls G, Lubbers T, Hadfoune M, Reisinger K, Heineman E, Greve JW, Buurman WA. Protection against early intestinal compromise by lipid-rich enteral nutrition through cholecystokinin receptors. Crit Care Med. 2010;38(7):1592-7.

86. Chang M, Kistler EB, Schmid-Schonbein GW. Disruption of the mucosal barrier during gut ischemia allows entry of digestive enzymes into the intestinal wall. Shock. 2012;37(3):297-305.

87. Caputo FJ, Rupani B, Watkins AC, Barlos D, Vega D, Senthil M, Deitch EA Pancreatic duct ligation abrogates the trauma hemorrhage-induced gut barrier failure and the subsequent production of biologically active intestinal lymph. Shock. 2007;28(4):441-6.

88. Kistler EB, Alsaigh T, Chang M, Schmid-Schonbein GW. Impaired small-bowe barrier integrity in the presence of lumenal pancreatic digestive enzymes leads to circulatory shock. Shock. 2012;38(3):262-7.

89. Chang M, Alsaigh T, Kistler EB, Schmid-Schonbein GW. Breakdown of mucin as barrier to digestive enzymes in the ischemic rat small intestine. PLoS One. 2012;7(6):e40087.

90. Malinoski DJ, Hadjizacharia P, Salim A, Kim H, Dolich MO, Cinat M Barrios C, Lekawa ME, Hoyt DB. Elevated serum pancreatic enzyme levels after hemorrhagic shock predict organ failure and death. J Trauma. 2009;67(3):445-9.

91. Mitsuoka H, Kistler EB, Schmid-Schonbein GW. Generation of in vivo activating factors in the ischemic intestine by pancreatic enzymes. Proc Natl Acad Sci U S A. 2000;97(4):1772-7.

92. DeLano FA, Hoyt DB, Schmid-Schonbein GW. Pancreatic digestive enzyme blockade in the intestine increases survival after experimental shock. Sci Transl Med. 2013;5(169):169ra11.

93. Lee YT, Wei J, Chuang YC, Chang CY, Chen IC, Weng CF, Schmid-Schonbein GW. Successful treatment with continuous enteral protease inhibitor in a patient with severe septic shock. Transplant Proc. 2012;44(3):817-9.

94. Fanous MY, Phillips AJ, Windsor JA. Mesenteric lymph: the bridge to future management of critical illness. JOP. 2007;8(4):374-99.

95. Deitch EA. Gut lymph and lymphatics: a source of factors leading to organ injury and dysfunction. Ann N Y Acad Sci. 2010;1207 Suppl 1:E103-11.

96. Deitch EA, Adams C, Lu Q, Xu DZ. A time course study of the protective effect of mesenteric lymph duct ligation on hemorrhagic shock-induced pulmonary injury and the toxic effects of lymph from shocked rats on endothelial cell monolayer permeability. Surgery. 2001;129(1):39-47.

97. Wohlauer MV, Moore EE, Harr J, Eun J, Fragoso M, Banerjee A, Silliman CC. Cross-transfusion of postshock mesenteric lymph provokes acute lung injury. J Surg Res. 2011;170(2):314-8. 
98. Dzieciatkowska M, Wohlauer MV, Moore EE, Damle S, Peltz E, Campsen J, Kelher M, Silliman C, Banerjee A, Hansen KC. Proteomic analysis of human mesenteric lymph. Shock. 2011;35(4):331-8.

99. Adams Jr CA, Xu DZ, Lu Q, Deitch EA. Factors larger than $100 \mathrm{kd}$ in posthemorrhagic shock mesenteric lymph are toxic for endothelial cells. Surgery. 2001;129(3):351-63.

100. Fang JF, Shih LY, Yuan KC, Fang KY, Hwang TL, Hsieh SY. Proteomic analysis of post-hemorrhagic shock mesenteric lymph. Shock. 2010;34(3):291-8.

101. Morishita K, Aiboshi J, Kobayashi T, Mikami S, Yokoyama Y, Ogawa K, Yokota H, Otomo Y. Lipidomics analysis of mesenteric lymph after trauma and hemorrhagic shock. J Trauma Acute Care Surg. 2012;72(6):1541-7.

102. Qin X, Dong W, Sharpe SM, Sheth SU, Palange DC, Rider T, Jandacek R, Tso $P$, Deitch EA. Role of lipase-generated free fatty acids in converting mesenteric lymph from a noncytotoxic to a cytotoxic fluid. Am J Physiol Gastrointest Liver Physiol. 2012:303(8):G969-78.

103. Osband AJ, Deitch EA, Hauser CJ, Lu Q, Zaets S, Berezina T, Machiedo GW, Rajwani KK, Xu DZ. Albumin protects against gut-induced lung injury in vitro and in vivo. Ann Surg. 2004;240(2):331-9.

104. Kaiser VL, Sifri ZC, Dikdan GS, Berezina T, Zaets S, Lu Q, Xu DZ, Deitch EA. Trauma-hemorrhagic shock mesenteric lymph from rat contains a modified form of albumin that is implicated in endothelial cell toxicity. Shock. 2005:23(5):417-25.

105. Gonzalez RJ, Moore EE, Ciesla DJ, Biffl WL, Offner PJ, Silliman CC. Phospholipase A(2)-derived neutral lipids from posthemorrhagic shock mesenteric lymph prime the neutrophil oxidative burst. Surgery. 2001;130(2):198-203.

106. Keshav S. Paneth cells: leukocyte-like mediators of innate immunity in the intestine. J Leukoc Biol. 2006;80(3):500-8.

107. Atkins JL, Hammamieh R, Jett M, Gorbunov NV, Asher LV, Kiang JG. Alpha-defensin-like product and asymmetric dimethylarginine increase in mesenteric lymph after hemorrhage in anesthetized rat. Shock. 2008;30(4):411-6.

108. Vandenbroucke RE, Vanlaere I, Van Hauwermeiren F, Van Wonterghem E, Wilson C, Libert C. Pro-inflammatory effects of matrix metalloproteinase 7 in acute inflammation. Mucosal Immunol. 2014;7(3):579-88.

109. Park SW, Kim M, Kim JY, Ham A, Brown KM, Mori-Akiyama Y, Ouellette AJ, D'Agati VD, Lee HT. Paneth cell-mediated multiorgan dysfunction after acute kidney injury. J Immunol. 2012;189(11):5421-33.

110. Takahashi N, Vanlaere I, de Rycke R, Cauwels A, Joosten LA, Lubberts E, van den Berg WB, Libert C. IL-17 produced by Paneth cells drives TNF-induced shock. J Exp Med. 2008;205(8):1755-61.

111. Park SW, Kim M, Brown KM, D'Agati VD, Lee HT. Paneth cell-derived interleukin-17A causes multiorgan dysfunction after hepatic ischemia and reperfusion injury. Hepatology. 2011;53(5):1662-75.

112. Lee HT, Kim M, Kim JY, Brown KM, Ham A, D'Agati VD, Mori-Akiyama Y. Critical role of interleukin-17A in murine intestinal ischemia-reperfusion injury. Am J Physiol Gastrointest Liver Physiol. 2013;304(1):G12-25.

113. Yi J, Slaughter A, Kotter CV, Moore EE, Hauser CJ, Itagaki K, Wohlauer M, Frank DN, Silliman C, Banerjee A, Peltz E. A "clean case" of systemic injury: mesenteric lymph after hemorrhagic shock elicits a sterile inflammatory response. Shock. 2015;44(4):336-40.

114. Reino DC, Pisarenko V, Palange D, Doucet D, Bonitz RP, Lu Q, Colorado I, Sheth SU, Chandler B, Kannan KB, Ramanathan M, da Xu Z, Deitch EA, Feinman R. Trauma hemorrhagic shock-induced lung injury involves a gut-lymph-induced TLR4 pathway in mice. PLoS One. 2011;6(8):e14829.

115. Matzinger $P$. The danger model: a renewed sense of self. Science. 2002:296(5566):301-5. 